\title{
Expression of Forkhead box P3 in tumour cells causes immunoregulatory function of signet ring cell carcinoma of the stomach
}

\author{
M Yoshii', H Tanaka*,', M Ohira', K Muguruma', T Iwauchi', T Lee', K Sakurai', N Kubo', M Yashiro', \\ T Sawada' and K Hirakawa'
}

'Department of Surgical Oncology, Osaka City University Graduate School of Medicine, I-4-3, Asahi-machi, Abeno-ku, Osaka 545-8585, Japan

\begin{abstract}
BACKGROUND: It was recently reported that the transcription factor Forkhead box P3 (FoxP3) is expressed not only in regulatory $T$ cells (Tregs) but also in cancer cells. The aim of this study was to clarify the clinical significance of FoxP3 expression in gastric carcinoma.

METHODS: We performed immunohistochemical staining of FoxP3 to examine the association of FoxP3 expression with clinicopathological features of 194 patients with gastric cancer who underwent surgical resection from 2000 to 2010 . We also investigated the immunosuppressive function of FoxP3 using gastric cancer cell lines.

RESULTS: Immunohistochemical staining indicated FoxP3-positive cells within tumour tissue including both Tregs and tumour cells. Forkhead box P3-positive tumour cells were observed in 79.3\% of signet ring cell carcinoma patients, and the expression of FoxP3 showed a significant correlation with lymph node metastasis. We showed that transforming growth factor- $\beta$ augmented FoxP3 mRNA expression in cell lines derived from signet ring cell carcinoma. Indoleamine-2,3-dioxygenase and galectin-I, key effectors of Treg-mediated immunosuppression, were downregulated by FoxP3 knockdown.

CONCLUSION: Our findings suggested that FoxP3 expression by tumour cells might have important roles in immune escape of gastric carcinoma, and be associated with the malignant potential of scirrhous gastric carcinoma.
\end{abstract}

British Journal of Cancer (2012) I 06, 1668-1674. doi:10.1038/bjc.2012.14I www.bjcancer.com

Published online 19 April 2012

(c) 2012 Cancer Research UK

Keywords: gastric cancer; signet ring cell carcinoma; metastasis

Regulatory $\mathrm{T}$ cells (Tregs) are naturally present in the immune system and have important roles in suppression of the host antitumour immune response. Regulatory $\mathrm{T}$ cells are classified into two types: one type is generated in the thymus and migrates to the periphery; the other is induced from naïve $\mathrm{T}$ cells by cytokines such as transforming growth factor- $\beta$ (TGF- $\beta$; Zou, 2006; Sakaguchi et al, 2010). Previous studies have pointed out that an increase in Tregs in tumour tissue is associated with the progression of many solid cancers such as breast cancer (Mansfield et al, 2009), malignant melanoma (Polak et al, 2007), oesophageal cancer, and gastric cancer (Mizukami et al, 2008; Shen et al, 2010). Regulatory $\mathrm{T}$ cells are characterised by constitutive expression of $\mathrm{CD} 25$ and the transcriptional factor Forkhead box P3 (FoxP3). The key role of FoxP3 in Tregs is induction of immune-suppressive function to maintain selftolerance. It is widely accepted that FoxP3 is the most reliable marker of Tregs, and is expressed in both mice and humans. It has recently been reported that FoxP3 expression is detected not only in Tregs but also in tumour cells such as melanoma cells (Ebert et al, 2008) and pancreatic carcinoma cells (Hinz et al, 2007). Furthermore, the relationship between FoxP3

*Correspondence: Dr H Tanaka; E-mail: hiroakitan@med.osaka-cu.ac.jp Received II November 20II; revised 20 February 2012; accepted 22 March 2012; published online 19 April 2012 expression by tumour cells and clinicopathological characteristics has been described in detail (Wang et al, 2010b). However, the detailed molecular mechanisms of FoxP3 expression in tumour cells remain unclear.

Gastric carcinoma is one of the most common malignancies in the world, but is especially common in Japan. Human scirrhous gastric carcinoma exhibits a number of unique biological properties such as extensive fibrosis with sparse tumour cell infiltration in the stroma, and has the worst clinical prognosis of any type of gastric carcinoma. Signet ring cell carcinoma is a diffuse type of carcinoma based on Lauren's classification, and is characterised by the potential to diffusely infiltrate the gastric wall. Advanced stage signet ring cell carcinoma shows a higher rate of lymph node metastasis than other types of carcinoma, with peritoneal dissemination similar to that of scirrhous gastric carcinoma (Hyung et al, 2002; Li et al, 2007). It is known that signet ring cell carcinoma patients have poor prognosis, although the reason is still unclear. Tumours, including gastric cancer, might rely on modulation of the expression of various molecules that mediate tumour-induced immunosuppression to escape from immune surveillance.

In this study, we investigated the expression of FoxP3 by gastric cancer cells and the correlation with tumour histological type on FoxP3 expression, to clarify whether FoxP3 expression by tumour cells is associated with induction of immunosuppression. 


\section{MATERIALS AND METHODS}

\section{Clinical samples and cell lines}

Human gastric carcinoma specimens were collected from 194 patients who underwent gastrectomy in the Department of Surgical Oncology, Osaka City University Graduate School of Medicine. The human cancer cell lines, OCUM-8, OCUM-12, OCUM-2M, and OCUM-2MD3 were established from scirrhous gastric carcinoma in our laboratory (Yashiro et al, 1996). MKN-7 and MKN-74 were derived from tubular adenocarcinoma of the stomach. Peripheral blood mononuclear cells (PBMCs) were isolated from healthy human volunteers by Ficoll-Paque density gradient centrifugation.

\section{Immunohistochemistry}

Paraffin-embedded sections were deparaffinised in xylene and rehydrated. Endogenous peroxidase was blocked with $3 \% \mathrm{H}_{2} \mathrm{O}_{2}$ for $15 \mathrm{~min}$. For FoxP3 staining, antigens were retrieved by autoclaving in $0.01 \mathrm{~m}$ citrate $(\mathrm{pH} 6.0)$ at $121^{\circ} \mathrm{C}$ for $15 \mathrm{~min}$, followed by a gradual cooldown to $70^{\circ} \mathrm{C}$ in an autoclave, and then a cooldown to $37^{\circ} \mathrm{C}$ by placing them at room temperature (Nakamura et al, 2007). For indoleamine-2,3-dioxygenase (IDO) and galectin-1 (Gal-1) staining, antigens were retrieved by autoclaving at $105^{\circ} \mathrm{C}$ for $10 \mathrm{~min}$. After blocking non-specific staining, sections were incubated overnight at $4{ }^{\circ} \mathrm{C}$ with a primary antibody. Goat polyclonal anti-FoxP3 antibody ( $1: 100$ dilution, AbCam, Cambridge, UK), rabbit polyclonal anti-IDO antibody (1:100 dilution, Santa Cruz Biotechnology Inc., Santa Cruz, CA, USA), and rabbit polyclonal anti-Gal- 1 antibody ( $1: 500$ dilution, $\mathrm{AbCam}$ ) were used as primary antibodies. The primary antibody was detected using a biotinylated secondary antibody. The signal was amplified by streptavidin-biotin complex formation and developed with diaminobenzidine followed by counterstaining with heamatoxylin. Finally, the slides were dehydrated and mounted.

The percentage of FoxP3-positive tumour cells per field was scored using a semiquantitative four-category grading system: $0=0-10 \%$, $1=11-50 \%, 2=51-80 \%$, and $3=81-100 \%$. And we defined 0 and 1 as negative, and 2 and 3 as positive staining. Two experienced investigators including a pathologist who was blinded to the clinical follow-up data independently scored the cases analysed in this study.

\section{Reverse transcription (RT)-PCR and quantitative real-time RT-PCR}

Total RNA was isolated from cell lines, tumour cells in clinical samples, and from PBMCs using Trizol reagent (Invitrogen, Carlsbad, CA, USA), and was used as a template for the synthesis of complementary DNA by RT using random primers (Invitrogen). PCR was carried out using FoxP3 (forward primer) $5^{\prime}$-GCCCTTGGACAAGGACCCGATG-3' ${ }^{\prime}$ and FoxP3 (reverse primer) $5^{\prime}$-CATTTGCCAGCAGTGGGTAGGA-3'. PCR involved 35 cycles of $94^{\circ} \mathrm{C}$ for $1 \mathrm{~min}$, $66^{\circ} \mathrm{C}$ for $1 \mathrm{~min}$, and $72{ }^{\circ} \mathrm{C}$ for $1 \mathrm{~min}$, with a final primer extension at $72{ }^{\circ} \mathrm{C}$ for $10 \mathrm{~min}$. PCR products were resolved using $1 \%$ agarose gel electrophoresis. Glyceraldehyde-3-phosphate dehydrogenase was also analysed to verify the integrity of the template cDNA preparations. We performed quantitative RT-PCR using TaqMan FoxP3, IDO, and Gal-1 gene expression assays (Applied Biosystems, Foster City, CA, USA, assay ID: Hs01085834, Hs00158032, and Hs00355202, respectively). Thermocycling was performed with an ABI Prism 7000 Sequence Detection System (Applied Biosystems) using an initial incubation at $95^{\circ} \mathrm{C}$ for $10 \mathrm{~min}$, followed by 50 cycles of $95^{\circ} \mathrm{C}$ for $15 \mathrm{~s}$ and $60^{\circ} \mathrm{C}$ for $1 \mathrm{~min}$. The $\Delta \Delta \mathrm{Ct}$ method was used to calculate values of FoxP3, IDO, and Gal-1 relative to GAPDH gene amplification.

\section{Western blot analysis}

Aliquots containing $30 \mu \mathrm{g}$ of total protein from lysate of cell lines were subjected to SDS-PAGE, and the protein bands were transferred to a polyvinylidene difluoride membrane (Amersham, Aylesbury, UK). The membrane was blocked with $3 \%$ non-fat dry milk in $1 \times$ PBS at room temperature for $1 \mathrm{~h}$, then probed with each primary antibody, 1:500 of anti-FoxP3 (PCH101; eBioscience, San Diego, CA, USA), 1:500 of anti-IDO (Santa Cruz Biotechnology, USA), 1:2000 of anti-Gal-1 (AbCam), or $1: 1000$ of anti- $\beta$-actin (Cell Signaling Tec., Danvers, MA, USA) at $4{ }^{\circ} \mathrm{C}$ overnight, followed by a peroxidase-labelled secondary antibody reactive with each primary antibody for $1 \mathrm{~h}$ at room temperature. Bands were detected using an enhanced chemiluminescence system (Amersham).

\section{Small interfering RNA (siRNA) treatment}

OCUM-2M cells were plated in 6-well plates and treated with siRNA targeting FoxP3 (s27192; Ambion, Austin, TX, USA), or with negative control siRNA (AM4611; Ambion), together with siPORT NeoFX agent (Ambion) for $8 \mathrm{~h}$ in a medium containing $10 \%$ FCS according to the manufacturer's instructions. At $8 \mathrm{~h}$ after transfection, the OCUM-2M cells were harvested and the efficacy of gene silencing was measured using quantitative RT-PCR. All experiments were repeated at least three times to assess reproducibility.

\section{Statistical analysis}

The correlation between the FoxP3 expression and clinicopathological characteristics was estimated using the $\chi^{2}$ test. Overall survival rates were analysed using the Kaplan-Meier method, and differences between survival curves were analysed using the log-rank test. The values obtained using quantitative RT-PCR were compared using Student's $t$-test. A $P$-value of $<0.05$ was considered statistically significant for all tests. All statistical analyses were performed using SPSS statistical software version 11.0.1 (SPSS Inc., Chicago, IL, USA).

\section{RESULTS}

\section{Correlation between FoxP3 and clinicopathological characteristics in gastric cancer tissue}

To examine FoxP3 expression in gastric cancer, we performed immunohistochemistry of 194 clinical samples using an anti-FoxP3 antibody. Nuclear immunostaining of FoxP3 was detected in lymphocytes around the tumour tissue in the primary tumour as well as lymph nodes (Figures 1A, B and C). The detected FoxP3positive lymphocytes were presumed to be mostly Tregs based on double CD4/FoxP3 immunohistochemical staining (Supplementary Figure 1). Interestingly, FoxP3 expression was also often localised in the nuclei of signet ring cell carcinoma tissues. However, few FoxP3-positive tumour cells were detected in poorly differentiated adenocarcinomas, and none were detected in well and moderately differentiated adenocarcinomas (Figures 1D-H). In addition, not only the primary signet ring cell carcinoma but also the metastatic lesions in the lymph node were FoxP3-positive. The frequency of FoxP3-positive tumour cells in signet ring cell carcinoma was observed to differ between patients. The expression level of FoxP3 was evaluated by investigators based on the percentage of FoxP3-positive tumour cells and was classified into four groups: $0-10 \%, 11-50 \%, 51-80 \%$, and $81-100 \%$. As shown in Table 1, 73 of 92 cases $(79.3 \%)$ of signet ring cell carcinoma displayed FoxP3-positive tumour cells. Compared with signet ring cell carcinoma, few cases showed positive expression in other histological carcinoma types assayed. On the other hand, the number of infiltrating FoxP3-positive Tregs into metastatic lymph nodes did not differ between intestinal type and signet ring cell carcinoma as judged by a similar assessment of CD4/FoxP3stained cells (Figures 1B and C). We defined 49 specimens with 

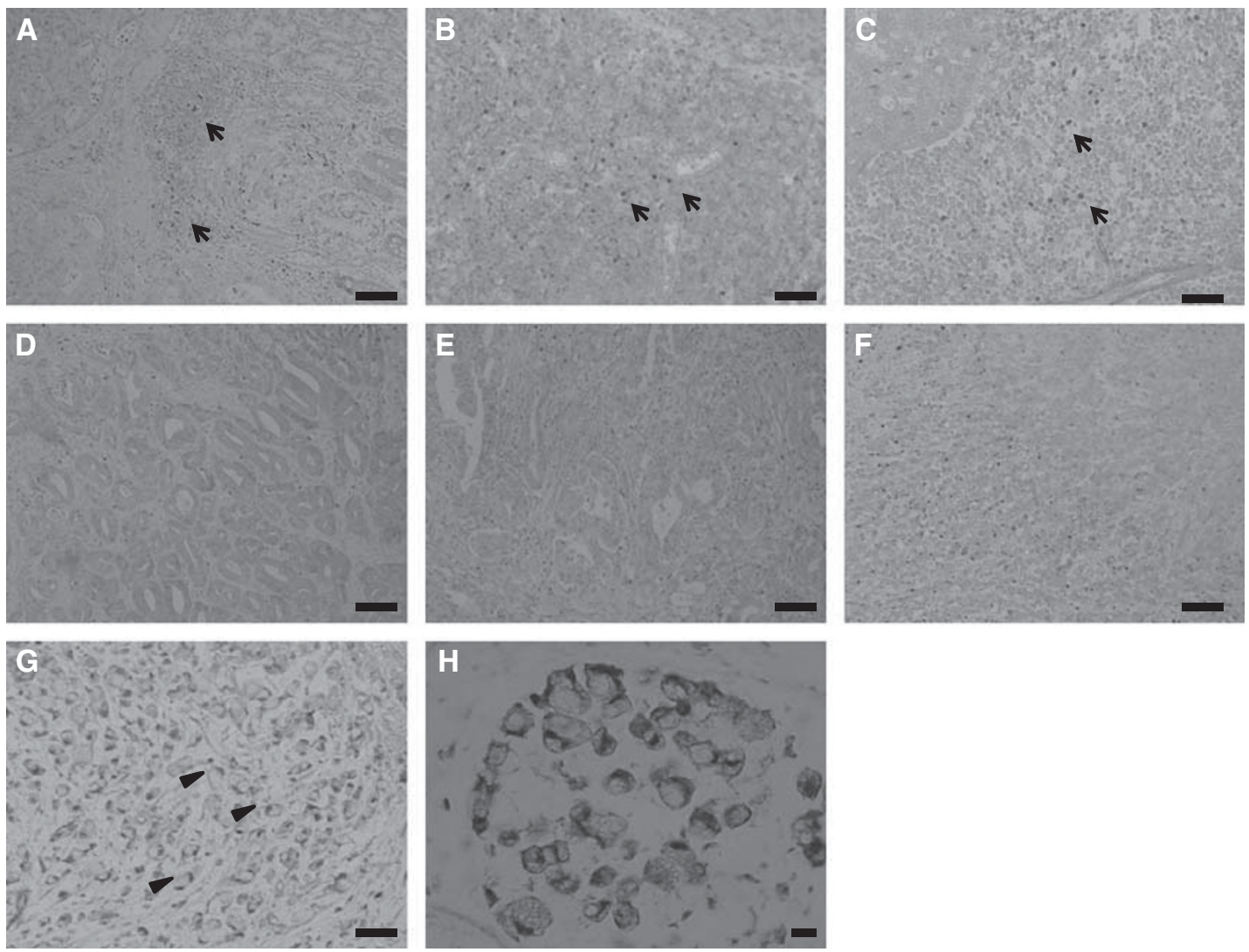

Figure I Immunohistochemical analysis of FoxP3 expression in gastric cancer tissue. Tumour tissue sections were immunohistochemically stained using an anti-FoxP3 antibody. Forkhead box P3-positive lymphocytes (arrows) had infiltrated into both primary lesions (A) and lymph nodes (B and C). Many FoxP3positive lymphocytes had infiltrated metastatic lymph nodes regardless of the tumour histological type $(\mathbf{C})$. We also detected FoxP3 staining of tumour cells (arrowheads; G). No FoxP3-positive tumour cells were detected in well-differentiated adenocarcinoma (D) or moderately differentiated adenocarcinoma $(\mathbf{E})$, and few FoxP3-positive tumour cells were detected in poorly differentiated adenocarcinoma (F). However, strong staining of FoxP3 was observed in the nuclei of cells with signet ring cell morphology $(\mathbf{G}$ and $\mathbf{H})$. Forkhead box P3 expression in signet ring cell carcinoma was classified into four groups according to the percentage of FoxP3-positive tumour cells: $0-10 \%,|I-50 \%, 5|-80 \%$, and $81-100 \%$. They were marked as 0 , I, 2, and 3, respectively. Groups 0 and I were defined as negative, and 2and 3 as positive. A-G: scale bar $=50 \mu \mathrm{m}$. $\mathbf{H}$ : scale bar $=10 \mu \mathrm{m}$.

Table I

Number of patients with FoxP3-positive tumour cells

\begin{tabular}{lrrrrrr}
\hline & \multicolumn{4}{c}{$\begin{array}{c}\text { FoxP3-positive } \\
\text { tumour cells }\end{array}$} & \\
\cline { 2 - 5 } Histological type & $\mathbf{0}$ & $\mathbf{I}$ & $\mathbf{2}$ & $\mathbf{3}$ & Total \\
\hline Well-differentiated adenocarcinoma & 14 & 0 & 0 & 0 & 14 \\
Moderately differentiated adenocarcinoma & 45 & 0 & 0 & 0 & 45 \\
Poorly differentiated adenocarcinoma & 38 & 5 & 0 & 0 & 43 \\
Signet ring cell carcinoma & 19 & 24 & 33 & 16 & 92 \\
\hline
\end{tabular}

scores 2 and 3 as positive expression and 43 with scores 0 and 1 as negative with FoxP3. The clinicopathological characteristics of the patients with signet ring cell carcinoma are summarised in Table 2. Of the 92 patients, 38 cases $(41.3 \%)$ were positive for lymphatic invasion but only 7 cases $(7.6 \%)$ were positive for venous invasion. A total of 34 cases $(37.0 \%)$ were diagnosed as pathological node positive and 52 patients were diagnosed as pathological stage I. Forkhead box P3 expression was significantly associated with node involvement and TNM stage IV (Table 2). However, there was no significant relationship of FoxP3 expression with prognosis. The 3 -year survival rate of patients with positive expression of FoxP3 in tumour tissue was $74.3 \%$ whereas those with negative expression was $86.5 \%$, indicating a potential association of FoxP3 with poor prognosis (Figure 2).

\section{Impact of FoxP3 expression on gastric cancer cell lines}

To examine the molecular mechanism, we first analysed FoxP3 mRNA expression in gastric cancer cell lines and several tumour tissues using RT-PCR. We analysed six different cell lines including OCUM-2M and OCUM-2MD3, OCUM-8 and -12 that are derived from signet ring cell-dominant gastric cancer, and MKN-7 and MKN-74 that are derived from cancer with histological features of well or moderately differentiated carcinoma. Previous reports suggested that there are various FoxP3 mRNA variants that arise owing to alternative splicing of the FoxP3 gene. It has been reported that FoxP3 mRNA in Tregs is expressed as two variants: full-length FoxP3 mRNA and a spliced version lacking exon 3. These two variants were detected following RT-PCR of PBMCs as band sizes of 608 and $503 \mathrm{bp}$, respectively (Figure 3A). The gastric cancer cell line, OCUM-2M expressed the same two variants as the Tregs, which suggests that FoxP3 in OCUM-2M might have a similar function as the FoxP3 in Tregs. However, the spliced variant of FoxP3 was absent in two other gastric cancer cell lines, OCUM-8 and OCUM-12. Moreover, we did not observe any FoxP3 mRNA expression in MKN-7 or MKN-74 cells, consistent with the immunohistochemical data. We therefore used OCUM-2M cells, which showed expression of the same FoxP3 mRNA variants as Tregs, for the following analyses. Although several patterns of isoforms were observed in gastric cancer cells from clinical samples, we detected the same pattern as OCUM-2M cells by RT-PCR (Figure 3A). 
Table 2 Correlation between the FoxP3 expression and clinicopathological characteristics of signet ring cell carcinoma patients $(n=92)$

\begin{tabular}{|c|c|c|c|}
\hline \multirow[b]{2}{*}{ Factor } & \multicolumn{2}{|c|}{ FoxP3 expression } & \multirow[b]{2}{*}{$P$-value } \\
\hline & Negative $(n=43)$ & Positive $(n=49)$ & \\
\hline Age (years) & \multicolumn{2}{|c|}{$61 \pm 13.6$} & \\
\hline \multicolumn{4}{|l|}{ Gender } \\
\hline Male & 20 & 24 & 0.837 \\
\hline Female & 23 & 25 & \\
\hline \multicolumn{4}{|c|}{ Lymphatic invasion } \\
\hline ly $(-)$ & 30 & 24 & 0.057 \\
\hline ly $(+)$ & 13 & 25 & \\
\hline \multicolumn{4}{|c|}{ Venous invasion } \\
\hline $\mathrm{v}(-)$ & 40 & 45 & I \\
\hline $\mathrm{v}(+)$ & 3 & 4 & \\
\hline \multicolumn{4}{|c|}{$T$} \\
\hline TI & 27 & 21 & 0.063 \\
\hline $\mathrm{T} 2-\mathrm{T} 4$ & 16 & 28 & \\
\hline \multicolumn{4}{|c|}{$N$} \\
\hline No & 33 & 25 & $0.017 *$ \\
\hline $\mathrm{NI}-\mathrm{N} 3$ & 10 & 24 & \\
\hline \multicolumn{4}{|l|}{ Stage } \\
\hline$|-|||$ & 41 & 36 & $0.005 *$ \\
\hline IV & 2 & 13 & \\
\hline
\end{tabular}

$* P<0.05$

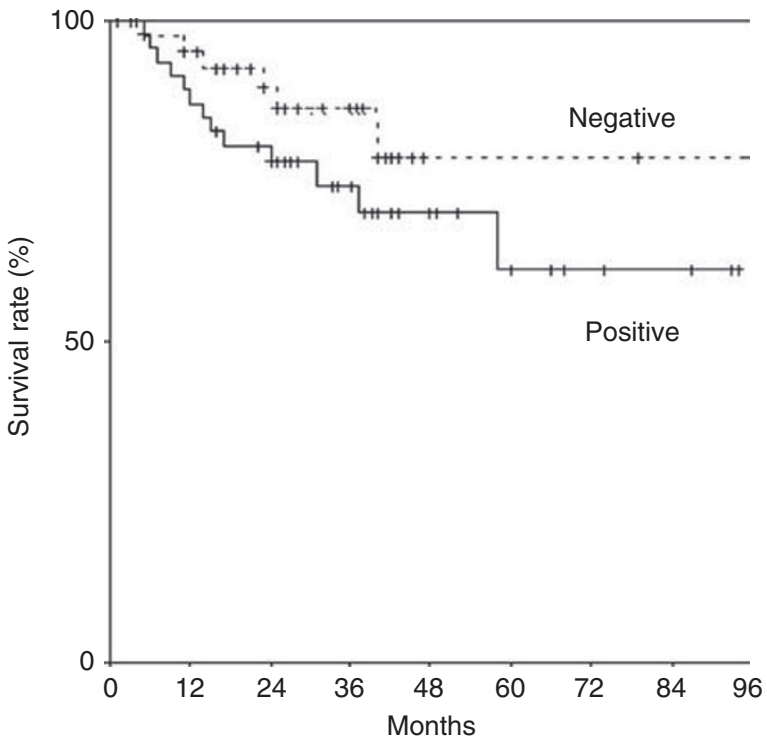

No. at risk

$\begin{array}{lllllcllll}\text { Negative } & 43 & 38 & 29 & 15 & 2 & 2 & 2 & 1 & 0 \\ \text { Positive } & 49 & 40 & 30 & 17 & 10 & 6 & 4 & 3 & 0\end{array}$

Figure 2 Survival curves of FoxP3-positive and -negative signet ring cell carcinoma patients. Kaplan-Meier curves of the overall survival of FoxP3positive and -negative signet ring cell carcinoma patients are shown. $P$ values between the FoxP3-positive group and the FoxP3-negative group were calculated using the log-rank test. There was no significant difference between positive and negative FoxP3 groups.

To clarify the immunoregulatory function of FoxP3-positive tumour cells, we examined the effect of TGF- $\beta$ on FoxP3 expression in OCUM-2M cells. Transforming growth factor- $\beta$ regulates T-cell function through the induction of FoxP3 expression. Stimulation with TGF- $\beta$ for $48 \mathrm{~h}$ significantly augmented the mRNA expression of FoxP3 in OCUM-2M cells. We also performed the same treatment in the other cell lines, including OCUM-8 and OCUM-12, which showed expression of only full-length FoxP3 mRNA variant. However, stimulation with TGF- $\beta$ did not change FoxP3 mRNA expression (Figure 3B).

As FoxP3 expression is associated with immunosuppression, we next determined if the expression of the immunosuppressive molecules, IDO and Gal-1, is associated with that of FoxP3 in tumour tissue. Using immunohistochemical staining, we detected the expression of both IDO and Gal-1 in tumour tissues including signet ring cell carcinoma (Figure 3C). The morphology of some of the IDO-positive cells was similar to that of macrophages or dendritic cells. Both the cytoplasmic and nuclear regions of tumour as well as bystander cells stained positive for Gal-1. We then analysed the effect of RNAi-mediated FoxP3 silencing on the mRNA expression of IDO and Gal-1 using the cancer cell line OUCM-2M, which constitutively expresses FoxP3. Knock down of FoxP3 in OCUM-2M cells significantly downregulated the mRNA expression of IDO and Gal-1, as analysed using quantitative RT-PCR (Figure 3D). Furthermore, we analysed the expression at protein level by western blot analysis. In OCUM-2M, OCUM-8, and OCUM-12, which showed mRNA expression of FoxP3, IDO, and Gal-1, we also detected the each protein expression (Figure 3E). By FoxP3 siRNA treatment to OCUM-2M cells, the protein expression of IDO and Gal-1 was downregulated (Figure 3F).

\section{DISCUSSION}

In this study, we demonstrated that FoxP3 was expressed in signet ring cell carcinoma of the stomach and might have relationship with immunosuppressive effect. Although Wang et al (2010a) previously reported that FoxP3 was recognised in gastric cancer tissue, our study is the first report to suggest immunoregulatory function of FoxP3 expressed in gastric cancer cells. We observed that FoxP3-positive tumour cells occur at a much higher frequency in signet ring cell carcinoma than in carcinomas of other histological types. The downregulation of IDO and Gal-1 expression by FoxP3 silencing in a cancer cell line suggests the immunosuppressive function of FoxP3 in tumours, indicating the differential immunosuppressive state of the background in gastric cancer. Our findings suggested that the signet ring cell carcinoma itself might be able to induce immune tolerance through FoxP3 gene expression.

Tumours are imprinted by the immunologic environment in which they form. Dunn et al advocated the term 'cancer immunoediting' to describe the process of protection and development of a tumour (Dunn et al, 2002). To improve the efficacy of immunotherapy against cancer, it is important to understand the balance between proinflammatory and immunosuppressive responses in antitumour immunity. Regulatory $\mathrm{T}$ cells have a central role in the regulation of immune responses to tumours. The amount of FoxP3 protein is critical for the Treg suppressor function. Our immunohistochemical staining showed that FoxP3-positive cells in tumour tissue included not only infiltrating Tregs but also cancer cells themselves. Importantly, FoxP3-positive cancer cells were confined to signet ring cell carcinoma. Signet ring cell carcinoma of the stomach frequently shows diffuse infiltrative growth called scirrhous cancer, lymph node metastasis, and peritoneal dissemination, which correlate with poor prognosis (Hyung et al, 2002; Li et al, 2007). However, the reason for this poor prognosis remains unclear. Factors such as depth of invasion, histological type, and lymph node metastasis are generally known as prognostic factors for gastric cancer. Our results of immunohistochemical staining did not demonstrate a significant relationship of FoxP3 expression with prognosis, 
A
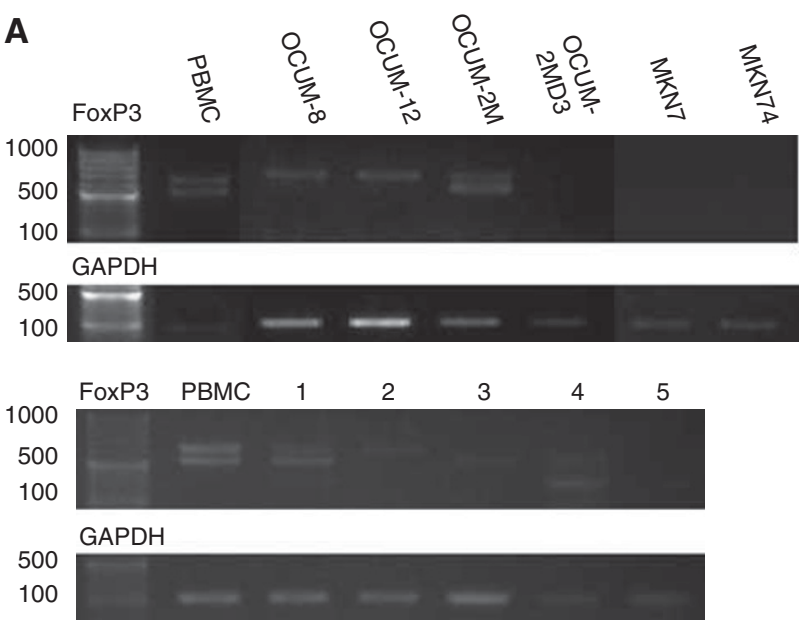

C
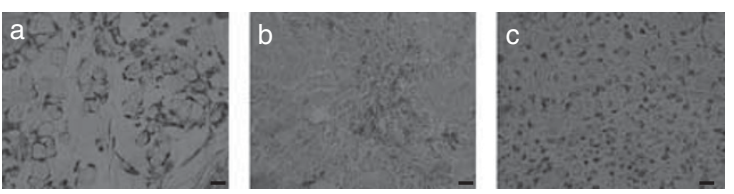

E

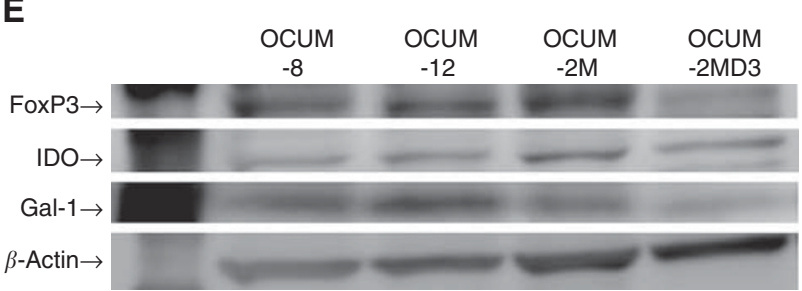

B

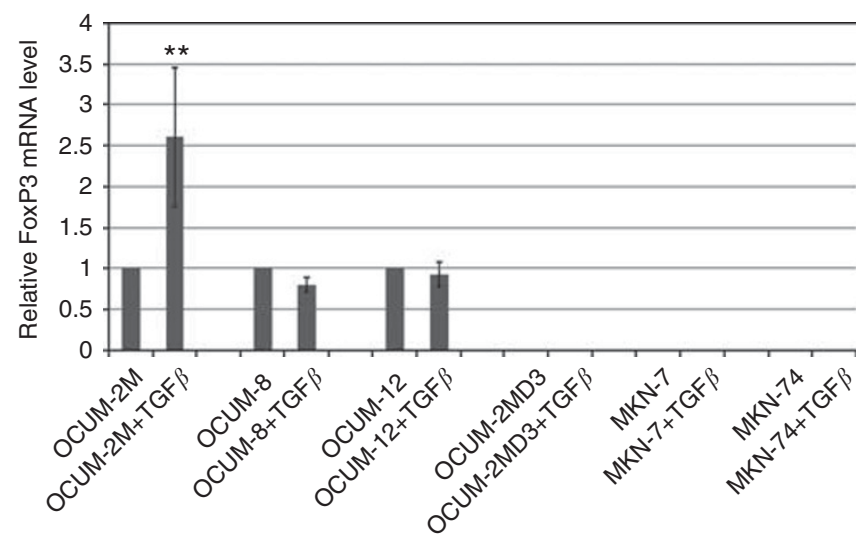

D
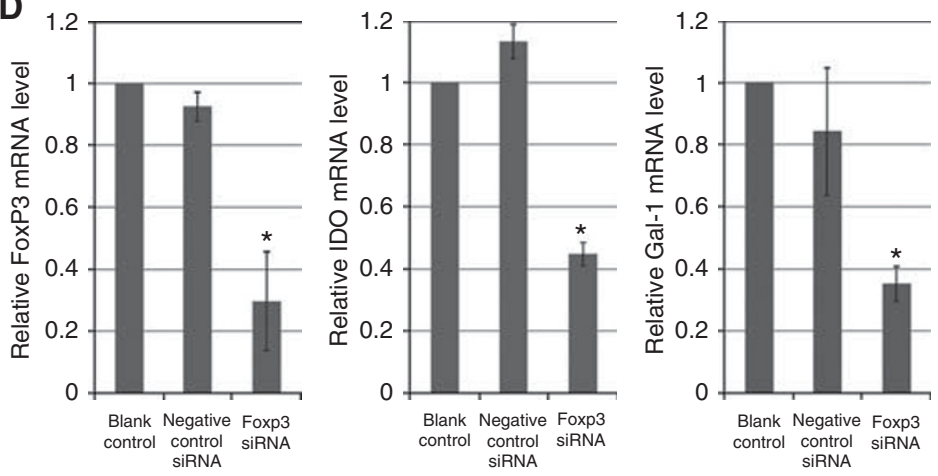

$\mathbf{F}$

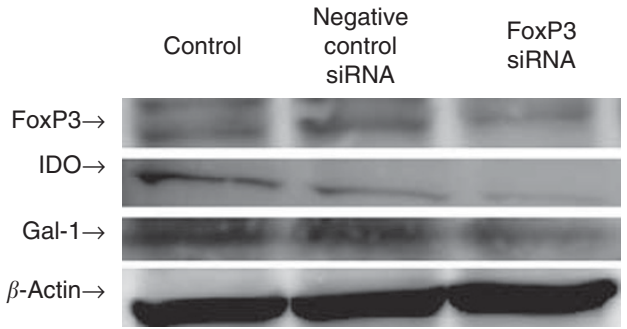

Figure 3 Expression and impact of FoxP3 on gastric cancer cell lines. (A) Expression of FoxP3 mRNA in gastric cancer cell lines and tissues. Forkhead box P3 mRNA expression in six gastric cancer cell lines and tumour cells from five cases were analysed by RT-PCR. In the OCUM-2M scirrhous gastric cancer cell line, FoxP3 mRNA was expressed as two variants similar to those in PBMCs. The upper band (608 bp in size) is considered to be full-length FoxP3 mRNA and the lower band (503 bp) is considered to be a $\Delta 3$ splice variant. Only the full-length FoxP3 mRNA was expressed in OCUM-8 and OCUM- I2 cells. MKN-7 and MKN-74 cells, which were derived from intestinal type cancer, showed no FoxP3 expression. In case I, FoxP3 mRNA was expressed as two variants similar to those in PBMCs. Some cases showed several patterns of mRNA expression, some showed no expression. GAPDH expression was used to verify the integrity of the template cDNA preparations. (B) Effect of TGF- $\beta$ on FoxP3 mRNA expression in gastric cancer cell lines. Stimulation with $10 \mu \mathrm{g} \mathrm{ml}^{-1}$ TGF- $\beta$ for $48 \mathrm{~h}$ induced a significant increase in FoxP3 mRNA expression in OCUM-2M cells (** $\left.P<0.0 \mathrm{I}\right)$. However, we observed no increase in the other cell lines. Bars, s.d.s. (C) Expression of the effectors of Treg-mediated immunosuppression IDO and Gal- I in gastric cancer tissue. Tumour tissue was immunohistochemically stained using anti-IDO and anti-Gal-I antibodies. Indoleamine-2,3-dioxygenase and Gal-I were strongly expressed in the nuclei of tumour cells in signet ring cell carcinoma $(\mathbf{A}$ and $\mathbf{C})$. Furthermore, IDO expression was also detected in stromal cells, which had the morphologic appearance of macrophages or dendritic cells (B). A-C: scale bar $=10 \mu \mathrm{m}$. (D) Effect of FoxP3 siRNA on IDO and Gal-I mRNA expression in OCUM-2M cells. The effect of FoxP3 siRNA on specific mRNA expression in OCUM-2M cells was analysed using quantitative RT-PCR. At $8 \mathrm{~h}$ after exposure to FoxP3 siRNA, the mRNA expression of FoxP3, IDO, and Gal-I was significantly downregulated relative to their respective expression in non-transfected cells (blank control) or in cells transfected with negative control siRNA (*P<0.05). Bars, s.d.s. (E and $\mathbf{F})$ Effect of FoxP3 siRNA on IDO and Gal-I protein expression in OCUM-2M cells. (E) The protein expression of FoxP3, IDO, and Gal-I was analysed in several gastric cancer cell lines by western blot analysis. In OCUM-2M, OCUM-8, and OCUM-12 we detected the protein expression. (F) Protein expression of IDO and Gal-I was downregulated in OCUM-2M cells by FoxP3 siRNA treatment.

because we did not show the direct evidence of FoxP3-induced capacity of cancer cells to metastasise or induce Tregs around tumour. We previously reported that TGF- $\beta$ produced by cancerassociated fibroblasts triggers the progression of scirrhous gastric carcinoma (Yashiro et al, 1996), indicating that FoxP3 in signet ring cells might be induced by TGF- $\beta$ produced by cells in the tumour microenvironment including fibroblasts, macrophage, or dendritic cells. However, our data that FoxP3 expression was 
associated with lymph node metastasis were consistent with Wang's report, suggesting correlation to host immunostatus (Maehara et al, 1997; Shu et al, 2006).

In vitro we confirmed that FoxP3 mRNA and FoxP3 protein are expressed in cell lines derived from signet ring cell carcinoma, but not in cell lines from differentiated adenocarcinoma. It has been previously reported that alternative splicing of the human FoxP3 gene can give rise to different FoxP3 variants. However, until now, it has been unclear whether each isoform has distinct functions (Smith et al, 2006). In this study, we observed differences in the expression of FoxP3 splicing variants among cell lines, indicating that there are probablyfunctional differences between OCUM-2M, and OCUM-8 and OCUM-12 owing to differentially spliced FoxP3. We selected the OCUM-2M cell line for further study because this cell line expresses both full-length FoxP3 and the isoform that lacks exon 3, which are the FoxP3 forms that are endogenously expressed in human $\mathrm{CD} 4{ }^{+} \mathrm{CD} 25^{+}$Tregs. Transforming growth factor- $\beta$, an immunosuppressive cytokine, inhibits immune responses by inducing FoxP3 expression and thereby promoting the generation of Tregs (Wan and Flavell, 2008). Augmentation of FoxP 3 mRNA in OCUM-2M cells by TGF- $\beta$ treatment suggested that the FoxP3 protein might have functional significance for cancer cells.

To determine if the FoxP3 expressed by tumours could induce an immunosuppressive environment, we next examined the ability of FoxP3 expressed in a gastric cancer cell line to regulate IDO and Gal-1 expression. Indoleamine-2,3-dioxygenase, an intracellular enzyme that catalyses tryptophan, strongly inhibits the development of immune responses by blocking T-cell activation, inducing $\mathrm{T}$-cell apoptosis and promoting the differentiation of naïve $\mathrm{T}$ cells into Tregs (Sakaguchi et al, 2010). Indoleamine-2,3-dioxygenase is expressed in various human cancer tissues and is involved in protecting tumours from being attacked by tumour-associated antigen-specific host cytotoxic T cells (Brandacher et al, 2006; Ino et al, 2006; Ino et al, 2008). Galectin-1, an $\alpha \beta$-galactoside binding protein with immune regulatory functions, is upregulated in many cancers, including melanoma, colon, bladder, and ovarian carcinoma, and contributes to the immunosuppression and

\section{REFERENCES}

Brandacher G, Perathoner A, Ladurner R, Schneeberger S, Obrist P, Winkler C, Werner ER, Werner-Felmayer G, Weiss HG, Gobel G, Margreiter R, Konigsrainer A, Fuchs D, Amberger A (2006) Prognostic value of indoleamine 2,3-dioxygenase expression in colorectal cancer: effect on tumor-infiltrating T cells. Clin Cancer Res 12: 1144-1151

Dunn GP, Bruce AT, Ikeda H, Old LJ, Schreiber RD (2002) Cancer immunoediting: from immunosurveillance to tumor escape. Nat Immunol 3: 991-998

Ebert LM, Tan BS, Browning J, Svobodova S, Russell SE, Kirkpatrick N, Gedye C, Moss D, Ng SP, MacGregor D, Davis ID, Cebon J, Chen W (2008) The regulatory $\mathrm{T}$ cell-associated transcription factor FoxP3 is expressed by tumor cells. Cancer Res 68: 3001-3009

Garin MI, Chu CC, Golshayan D, Cernuda-Morollon E, Wait R, Lechler RI (2007) Galectin-1: a key effector of regulation mediated by CD4+ CD25 + T cells. Blood 109: 2058-2065

Hinz S, Pagerols-Raluy L, Oberg HH, Ammerpohl O, Grussel S, Sipos B, Grutzmann R, Pilarsky C, Ungefroren H, Saeger HD, Kloppel G, Kabelitz D, Kalthoff H (2007) Foxp3 expression in pancreatic carcinoma cells as a novel mechanism of immune evasion in cancer. Cancer Res 67: 8344-8350

Hyung WJ, Noh SH, Lee JH, Huh JJ, Lah KH, Choi SH, Min JS (2002) Early gastric carcinoma with signet ring cell histology. Cancer 94: 78-83

Ino K, Yamamoto E, Shibata K, Kajiyama H, Yoshida N, Terauchi M, Nawa A, Nagasaka T, Takikawa O, Kikkawa F (2008) Inverse correlation between tumoral indoleamine 2,3-dioxygenase expression and tumorinfiltrating lymphocytes in endometrial cancer: its association with disease progression and survival. Clin Cancer Res 14: 2310-2317 apoptosis of immune cells, particularly $\mathrm{T}$ cells (Rubinstein et al, 2004; Rabinovich, 2005; Kuo et al, 2011). Galectin-1 is also expressed by Tregs and is upregulated upon T-cell receptor activation. Blocking of Gal-1 markedly reduced the immune inhibitory effects of Tregs, and Tregs from Gal-1-deficient mice displayed reduced Treg cell activity (Garin et al, 2007; Kubach et al, 2007; Shevach, 2009).

We detected IDO and Gal-1 expression in clinical samples of signet ring cell carcinoma as well as in cancer cell lines, and RNA silencing of FoxP3 downregulated both mRNA and protein levels of IDO and Gal-1 in a gastric cancer cell line. These results suggested that FoxP3 transcription is important for tumour expression of IDO and Gal-1, which may subsequently induce immunosuppression.

Our results are consistent with previous reports that assessed FoxP3 expression by tumour cells. Hinz et al (2007) reported that FoxP3-expressing pancreatic carcinoma cells suppressed T-cell proliferation and that knock down of FoxP3 by siRNA treatment reduced the suppressive activity of these cells. Ebert et al (2008) demonstrated FoxP3 expression in melanoma cells and suggested that FoxP3 expression in tumour cells might endow tumour cells themselves with immune-suppressive activity. Wang et al (2010b) reported clinical characteristics of FoxP3-expressing hepatocellular carcinoma tissues and suggested that FoxP3 staining might be associated with a high risk of hepatocellular carcinoma.

In conclusion, we demonstrated that signet ring cell carcinoma cells might have a Treg-like activity, which would allow them to escape from immune surveillance, thereby resulting in cancer progression such as lymph node metastasis. These findings might provide new perspectives regarding immunotherapeutic strategies against scirrhous gastric carcinoma. Our results might not only improve the efficacy of immunotherapies but also would help to guide decisions regarding the combination of cancer vaccine and other treatment modalities such as surgery, radiotherapy, chemotherapy, and targeted therapy.

Supplementary Information accompanies the paper on British Journal of Cancer website (http://www.nature.com/bjc)

Ino $\mathrm{K}$, Yoshida $\mathrm{N}$, Kajiyama $\mathrm{H}$, Shibata $\mathrm{K}$, Yamamoto $\mathrm{E}$, Kidokoro $\mathrm{K}$, Takahashi N, Terauchi M, Nawa A, Nomura S, Nagasaka T, Takikawa O, Kikkawa F (2006) Indoleamine 2,3-dioxygenase is a novel prognostic indicator for endometrial cancer. Br J Cancer 95: 1555-1561

Kubach J, Lutter P, Bopp T, Stoll S, Becker C, Huter E, Richter C, Weingarten P, Warger T, Knop J, Mullner S, Wijdenes J, Schild H, Schmitt E, Jonuleit H (2007) Human CD4 + CD25 + regulatory T cells: proteome analysis identifies galectin-10 as a novel marker essential for their anergy and suppressive function. Blood 110: 1550-1558

Kuo PL, Hung JY, Huang SK, Chou SH, Cheng DE, Jong YJ, Hung CH, Yang CJ, Tsai YM, Hsu YL, Huang MS (2011) Lung cancer-derived galectin-1 mediates dendritic cell anergy through inhibitor of DNA binding 3/IL-10 signaling pathway. J Immunol 186: 1521-1530

Li C, Kim S, Lai JF, Hyung WJ, Choi WH, Choi SH, Noh SH (2007) Advanced gastric carcinoma with signet ring cell histology. Oncology 72: 64-68

Maehara Y, Tomisaki S, Oda S, Kakeji Y, Tsujitani S, Ichiyoshi Y, Akazawa K, Sugimachi K (1997) Lymph node metastasis and relation to tumor growth potential and local immune response in advanced gastric cancer. Int J Cancer 74: 224-228

Mansfield AS, Heikkila PS, Vaara AT, von Smitten KA, Vakkila JM, Leidenius MH (2009) Simultaneous Foxp3 and IDO expression is associated with sentinel lymph node metastases in breast cancer. BMC Cancer 9: 231

Mizukami Y, Kono K, Kawaguchi Y, Akaike H, Kamimura K, Sugai H, Fujii $\mathrm{H}$ (2008) Localisation pattern of Foxp3 + regulatory $\mathrm{T}$ cells is associated with clinical behaviour in gastric cancer. $\mathrm{Br} J$ Cancer 98: $148-153$ 
Nakamura T, Shima T, Saeki A, Hidaka T, Nakashima A, Takikawa O, Saito S (2007) Expression of indoleamine 2, 3-dioxygenase and the recruitment of Foxp3-expressing regulatory $\mathrm{T}$ cells in the development and progression of uterine cervical cancer. Cancer Sci 98: 874-881

Polak ME, Borthwick NJ, Gabriel FG, Johnson P, Higgins B, Hurren J, McCormick D, Jager MJ, Cree IA (2007) Mechanisms of local immunosuppression in cutaneous melanoma. Br J Cancer 96: 1879-1887

Rabinovich GA (2005) Galectin-1 as a potential cancer target. Br J Cancer 92: $1188-1192$

Rubinstein N, Alvarez M, Zwirner NW, Toscano MA, Ilarregui JM, Bravo A, Mordoh J, Fainboim L, Podhajcer OL, Rabinovich GA (2004) Targeted inhibition of galectin-1 gene expression in tumor cells results in heightened T cell-mediated rejection; A potential mechanism of tumorimmune privilege. Cancer Cell 5: 241-251

Sakaguchi S, Miyara M, Costantino CM, Hafler DA (2010) FOXP3 + regulatory $\mathrm{T}$ cells in the human immune system. Nat Rev Immunol 10: 490-500

Shen Z, Zhou S, Wang Y, Li RL, Zhong C, Liang C, Sun Y (2010) Higher intratumoral infiltrated Foxp3 + Treg numbers and Foxp $3+/ \mathrm{CD} 8+$ ratio are associated with adverse prognosis in resectable gastric cancer. J Cancer Res Clin Oncol 136: 1585-1595
Shevach EM (2009) Mechanisms of foxp3 $+\mathrm{T}$ regulatory cell-mediated suppression. Immunity 30: 636-645

Shu S, Cochran AJ, Huang RR, Morton DL, Maecker HT (2006) Immune responses in the draining lymph nodes against cancer: implications for immunotherapy. Cancer Metastasis Rev 25: 233-242

Smith EL, Finney HM, Nesbitt AM, Ramsdell F, Robinson MK (2006) Splice variants of human FOXP3 are functional inhibitors of human CD4+ T-cell activation. Immunology 119: 203-211

Wan YY, Flavell RA (2008) TGF-beta and regulatory T cell in immunity and autoimmunity. J Clin Immunol 28: 647-659

Wang LH, Su L, Wang JT (2010a) Correlation between elevated FOXP3 expression and increased lymph node metastasis of gastric cancer. Chinese Med J 123: 3545-3549

Wang WH, Jiang CL, Yan W, Zhang YH, Yang JT, Zhang C, Yan B, Zhang W, Han W, Wang JZ, Zhang YQ (2010b) FOXP3 expression and clinical characteristics of hepatocellular carcinoma. World J Gastroenterol 16: 5502-5509

Yashiro M, Chung YS, Kubo T, Hato F, Sowa M (1996) Differential responses of scirrhous and well-differentiated gastric cancer cells to orthotopic fibroblasts. Br J Cancer 74: 1096-1103

Zou W (2006) Regulatory T cells, tumour immunity and immunotherapy. Nat Rev Immunol 6: 295-307

This work is published under the standard license to publish agreement. After 12 months the work will become freely available and the license terms will switch to a Creative Commons Attribution-NonCommercial-Share Alike 3.0 Unported License. 